\title{
Innovation regional planning and latent dimensions: the case of the Algarve region
}

\author{
Hugo Pinto · João Guerreiro
}

Received: 10 April 2007 / Accepted: 13 August 2008

C) Springer-Verlag 2008

\begin{abstract}
Regional innovation systems (RSI) concept is an important theoretical framework to analyse regional profiles of regions when trying to understand Innovation but it has also been used by practioners to design and implement policies. This study hopes to contribute to the understanding of the Algarve RSI, a peripheral Portuguese region in the National and European framework, where an economic growth is supported by Tourism, which leaves it out of the group of poorest regions when the GDPpc indicator is taken in account. The regional profile, the comparison with the other European regions and the characterisation of RSI following developed typologies are discussed in this paper. Through the analysis of 175 regions of the EU 15 the study seeks to find the dimensions underlying the innovative phenomena and to create homogeneous groups of regions that display similar profiles. Factorial Analysis was used to reduce the dimension of data from a barrage of regional indicators such as: Critical Mass of Territories, Economic Performance, Level of Wealth, Employment Market, Sectoral Structure of the Economy, Age Group Structure, Education and Training, Technological Employment, R\&D and Patents. Having determined the four main factors with significant results (Technological Innovation, Human Capital, Economic Structure and Availability of the Employment Market) what followed was a hierarchical analysis of Clusters, resulting in five groupings of regions: Disadvantaged Regions, Average Regions, Central Regions, Large Economic Centres and Innovating
\end{abstract}

\footnotetext{
H. Pinto $(\varangle)$

University of the Algarve, Campus de Gambelas, Pavilhão A5, 8000 Faro, Portugal

e-mail: hpinto@ualg.pt

H. Pinto

CES-Centre for Social Studies, University of Coimbra, Coimbra, Portugal

J. Guerreiro

University of the Algarve, Campus de Gambelas, Pavilhão A5, 8000 Faro, Portugal

e-mail: jguerreiro@ualg.pt
} 
Regions. A synthesis of the recent Regional Innovation Strategies for the Algarve is presented including previous experiences (Ettirse and INOVAlgarve) and the Algarve's Regional Innovation Plan, which will try to create a pathway for regional development supported by knowledge-based activities for a more diversified regional economy.

\section{JEL Classification $\mathrm{C} 4 \cdot \mathrm{O} 2 \cdot \mathrm{O} 3 \cdot \mathrm{R} 5$}

\section{Introduction}

Innovation has gained importance within the current political agenda, OECD (2005) and European Commission (2004), since it has been recognized as the key factor to growth and competitiveness. Economic theory and related research, including growth accounting (Solow 1956, Solow 1957; Denison 1967; and Abramovitz 1962); new growth theory (Romer 1986 and 1990; and Lucas 1988); and the technological gap models of Fagerberg (1991) and Fagerberg et al. (1997) created unequivocal evidence that innovation and technological development crucially impact economic development.

The interest of innovation for regional development has grown since the mid-1990 s with the intensification of globalisation. The relation between innovation and regional development is complex, since innovative activities vary even in regions with similar technological profiles. These differences come from differences in educational and cultural development, access to markets, technological advantages, investment and institutional co-operation. These different characteristics confer upon regions different vocations or specialization in the global economy which create asymmetric economic performances. Currently Regional Innovations Systems (RSI) research is in the spotlight of the debate, not only because of its interesting theoretical achievements in analysing very complex and diverse innovative profiles and trajectories, but also by its operational value and continuous utilization for regional strategies and planning. Nevertheless, innovative industries tend to concentrate in places in which there exists a favourable environment for innovation. Developing innovation strategies does not guarantee development, because in addition to these strategies there are numerous other factors and issues that limit their implementation and these factors vary with different territorial contexts. A strategy for innovation must focus on a set of executable innovative actions, drawing upon regional competitive advantages, the innovation framework and goals.

The European Union (EU) has prepared several documents that state the interest of innovation, which culminated in the ambitious Lisbon Strategy. In Portugal it has influenced the Technological Plan, a national political agenda proposed for growth based on innovation, science and competitive enterprises. While interest in this agenda varies across Portugal, the Portuguese region of The Algarve, the interest in innovation is strong and not recent. The region was the first in Europe to create a trans-border BIC (European Commission Business Innovation Centre) in 1995, a body focused on innovation in SME (small and medium enterprises). The Algarve also developed Ettirse, a regional strategy for technology-transfer, which was followed by INOVAlgarve, a regional innovating actions programme. In the ex-post evaluation of this programme there emerged a need for a regional innovation plan which is a plan that 
puts forward the regional options for development, in terms of innovation, which in turn goes hand in hand with other regional policy prepared documents, such as PROTALGARVE (territory) or the Regional Development Strategy for 2007-2013.

This paper seeks to contribute to the consolidation of the RSI concept, showing the regional innovative diversity in the first fifteen European Union member state regions. Secondly, focus is on the Algarve, and how this region has strategically deployed the innovation theme over the last decade and introducing the provisions of the recent Algarve Regional Innovation Plan.

\section{Systemic innovation: from national paradigm to regional scale}

The emergence of the chain-linked model of Kline and Rosenberg (1986) provided evidence that innovation does not appear in society in a casual way and if some measures are taken into account and certain kinds of environment are developed, innovation tends to occur with more ease thus creating the basis for the innovation system approach to development. The systemic view of innovation reflects on the multiplicity of actors that participate in innovative processes, with their interactions and set of rules, organisation and institutions (Amable and Petit 2001). This view facilitates the inclusion, not only of economic factors, but also institutional, organisational, social and policy factors, Acs and Varga (2002). This system is always localised (Ferrão 2002) once it happens in the sequence of a set of relations that are territorially limited for each of the involved actors. The National Innovation Systems (NSI) approach believes that the national level is adequate to define these relations. The origin of this concept is given to Christopher Freeman, Richard R. Nelson and Bengt-Ake Lundvall. A NSI can be understood as the group of linked institutions, defined at the national scale, that develop policies that affect knowledge creation and transfer, innovative activities and diffusion that are constituted by a formal segment (public and private institutions) and an informal segment (based on learning processes and production and consumption routines).

The growing relevance of smaller territorial contexts brought the Regional Innovation Systems (RSI) concept into the mainstream of innovation policy discussions and research. Silva and Silva (2000) observe that the importance of European regional policy gave pertinence to the regional scale as an analytical and policy-making unit. The Oslo Manual also shows the major importance of the regional environment for the promotion of innovation and innovative capacities of enterprises. Regional disparities can be substantial, and the identification of these characteristics is crucial in the elaboration of adequate and useful policies (OECD 2005).

A Regional Innovation System may be defined as the group of actors and organisations (enterprises, universities, and research centres) engaged in regional innovation and learning (Doloreux and Bitard 2005), and characterised by the existence of territorial, intangible, institutional and relational resources (Guerreiro (2005)). Despite the huge interest in regional factors, the concept of RSI remains ambiguous (Doloreux and Bitard 2005). Sometimes RSIs are understood as small-scaled NSI. This notion fails to recognize the regional specificities of actors, institutions, relationships and attributes. RSIs are often criticized because sometimes their focus underestimates the external networks and institutions, Uyarra (2007). It is important to remember 
that any RSI is self-sufficient and its success depends on the links with knowledge networks, interactions with other RSI, their primary clusters, and national and global economies (Cooke 1998 and Guerreiro 2005). Regions are not isolated islands but open systems and their policy design and implementation should take this into account. An important discussion is whether RSIs exist in all regions. Some researchers assure that all regions have some kind of RSI, even if it is weak in terms of territorial boundaries, innovative performance or interaction between actors. Another approach considers that an RSI only exists if some minimal requirements are present in the analysed territory. The concept of system depends on the existence of relations among components, which is in fact a major gap in most cases when taking the RSI concept to an operational context. These constraints did not prevent regional authorities from adopting and absorbing the RSI concept and thus an increasing number of regions have or intend to become dynamic RSIs. The RSI literature has grown into an extensive body of research in the last decade beginning with the seminal work of Braczyc et al. (1998). In addition to the use of the RSI concept in research has been its adoption as a comprehensive framework for guiding implementation of innovation policies in diverse regional contexts. The flexibility of the concept and the coherence with the European Regional Policy context is helpful in developing policy. In operational terms Evangelista et al. (2001) suggest that RIS in Europe can be normally defined at the NUTS II level, which incorporates the majority of the EU administrative regions. A tendency among policy-makers is to capture the best practices of innovating regions in order to replicate their success. Limited results have been achieved by applying similar strategies without taking into account regional differences in related attributes. Regional policy should, of course, be designed and implemented taking into account a region's historical trajectory and how it affects change in the territory.

\section{The innovative profile of the Algarve}

\subsection{Presentation of the region}

The Algarve is a Portuguese region known for its specialisation in Tourism. It is the main vacation destination for the Portuguese and an important destination for the English, Irish, German and Dutch. From 1991 to 2001, the region had the highest population growth among other NUTS II level Portuguese regions. Within the next Financial Framework of EU (2007-2013) the Algarve has been removed from the group of EU NUTS II poor regions (Convergence Objective) and is in "phasing-out" period, a process that results in the reduction of European Structural Funds for the region.

The analysis of regional indicators (Table 1) of the Third Cohesion Report, European Commission (2004) and the Regional Trend Chart on Innovation (Hollanders 2003), reveals strong heterogeneity. In fact, these asymmetries are evident; the differences in GDPpc reflect huge discrepancies at the economic level. Education and training also show important contrasts. In terms of critical mass the EU has regions with variable population dimensions. The Algarve shows a low or limited population level with density below the average of the 175 analysed regions. The economic level 
is above average values due to the enlargement that led to an enrichment statistical process. Labour force is concentrated within the services sector, but the Primary sector has greater weight when compared to other regions. Industry is almost non-existent. The Algarve has positive indicators in employment and an age structure similar to the European average. The major deficits are related to human capital: $80 \%$ of the population has an inferior/low level of education, tertiary education is limited (about $7 \%$ of population) and life-long learning is a small residual. Innovation indicators have great weaknesses, in relation to inputs, the effort in $R \& D$ (in particular private) is very low, and medium/high tech sectors of are almost non-existent, which result in almost no innovation outputs.

\subsection{European regions in analysis}

The following analysis seeks to underline European diversity in terms of innovative profiles by examining the latent dimensions of this phenomenon and creating homogeneous groups of regions. Based on the analysis of two sets of regional data above cited, a decision was made to analyse the 175 European regions that were present in both data bases. A set of 30 regional indicators, related to territorial critical mass, economic performance, wealth level, labor market, economic structure, age structure, education and training, technologic employment and patent registration is used in the analysis to follow.

It is important to verify expected correlation levels among the variables and thus to ensure evidence of expected relations given findings in other empirical investigations, e.g., positive relationships between technological variables and GDP. Several significant correlations were detected among the analysed variables, ${ }^{1}$ which increased the relevance and usefulness of a factor analysis.

In the factor analysis, selection of the number of factors to retain, we used the Kaiser criteria, choosing the factors with Eigenvalues (explained variance) higher than 1 . Four factors satisfied this criterion, explaining $76.8 \%$ of the total variance, an acceptable value. ${ }^{2}$ The factor loadings did not produce understandable latent dimensions. To solve this problem Varimax rotation was conducted in order to minimize the number of variables with high loadings on each factor. The following definitions of the latent dimensions of Innovation where thus made more interpretable. Factor 1 (explains 26,03\% of Data total variance) is labeled: Technological Innovation because it contains variables related to patents, private $R \& D$ and employment in high/medium level technology. Factor 2 (explains $1,42 \%$ of data variance) is labeled Human Capital, because it includes all variables related to education and training and

\footnotetext{
1 Using Spearman's Ro and Pearson's R significant correlations were found among several variables including GDP, Patents, R\&D, Education, Employment and Tech Employment.

2 Methodological steps: after several attempts a choice was made to select the high positively correlated variables that seemed strongly connected to innovative phenomena and that successfully passed the requirements to use Factorial Analysis. The extraction resulted in very high commonalities (the variable's variance that is explained by the common factors). The Kaiser-Meyer-Olkin (KMO $=0,767$ ) and the Bartlett's Sphericity tests were used to validate the utilization of Factorial Analysis. The extracted factors were internally consistent, all four factors scored more than 0,6 in the Cronbach's Alpha.
} 
Table 1 Descriptive statistics and the Algarve (Source Adapted from Pinto 2006a)

\begin{tabular}{|c|c|c|c|c|}
\hline Variable & Algarve & Minimum & Maximum & Average \\
\hline Inhabitants, 2001 & 394 & 26 & 11,055 & 2203.8 \\
\hline Population density (hab./ $\left./ \mathrm{km}^{2}\right)-2001$ & 79.8 & 3.3 & 6015.5 & 333.04 \\
\hline GDP growth (average percentage 1995-2001) & 5.4 & -1 & 9.5 & 2.64 \\
\hline GDP per capita $(2001$ EU15 = 100) & 10,908 & 8,112 & 48,920 & 21,209 \\
\hline GDPpc mean 1999-2000-2001 EU15=100 & 72.4 & 52.7 & 217.3 & 94.87 \\
\hline GDPpc (2001 EU25=100) & 71.4 & 50.6 & 217.8 & 95 \\
\hline $\begin{array}{l}\text { Employment in agriculture (percentage of } \\
\text { total 2002) }\end{array}$ & 79.4 & 57.8 & 238.5 & 104 \\
\hline $\begin{array}{l}\text { Employment in industry (percentage of total } \\
\text { 2002) }\end{array}$ & 9.7 & 0.1 & 36.5 & 6.16 \\
\hline $\begin{array}{l}\text { Employment in services (percentage of total } \\
\text { 2002) }\end{array}$ & 21.3 & 7.7 & 43.3 & 27.81 \\
\hline $\begin{array}{l}\text { EPO patents for million inhabitants (average } \\
\text { 1999-2000-2001) }\end{array}$ & 69 & 25.3 & 91.5 & 65.58 \\
\hline $\begin{array}{l}\text { Employment rate (employed } 15-64 \text { years old as } \\
\text { percentage of population } 15-64 \text { years old) }\end{array}$ & 68.6 & 41.9 & 78.4 & 63.79 \\
\hline Unemployment rate $(2002)$ & 5.3 & 2 & 27.1 & 8.28 \\
\hline $\begin{array}{l}\text { Long duration Unemployment (as percentage of } \\
\text { unemployed) (2002) }\end{array}$ & 28.2 & 0 & 76.1 & 36.16 \\
\hline Women unemployment rate (2002) & 6.7 & 1.8 & 35.6 & 9.85 \\
\hline Young unemployment rate (2002) & 14.3 & 3.4 & 59.5 & 16.54 \\
\hline Percentage of population $<15$ years old (2000) & 14.7 & 2.3 & 23.8 & 16.55 \\
\hline Percentage of Population 15-64 years old (2000) & 66.6 & 61.6 & 72.1 & 66.66 \\
\hline Percentage of population $65+$ years old (2000) & 18.7 & 8.1 & 24.7 & 16.63 \\
\hline $\begin{array}{l}\text { Population 25-64 years old with low education } \\
\text { (Percentage of total-2002) }\end{array}$ & 80.4 & 3.9 & 86.3 & 36.25 \\
\hline $\begin{array}{l}\text { Population 25-64 years old with medium educa- } \\
\text { tion (Percentage of total-2002) }\end{array}$ & 12.9 & 8.7 & 70.9 & 43.44 \\
\hline $\begin{array}{l}\text { Population 25-64 years old with high education } \\
\text { (Percentage of total-2002) }\end{array}$ & 6.7 & 4.8 & 41.4 & 20.13 \\
\hline Tertiary education (2002) & 6.85 & 4.84 & 41.66 & 20.24 \\
\hline Life-long learning (2002) & 2.01 & 0.13 & 25.2 & 7.63 \\
\hline $\begin{array}{l}\text { Employment in medium/high technology } \\
\text { industries (2002) }\end{array}$ & 0.46 & 0.1 & 21.24 & 6.64 \\
\hline $\begin{array}{l}\text { Employment in medium/high technology services } \\
\text { (2002) }\end{array}$ & 0.68 & 0.29 & 8.78 & 2.92 \\
\hline Public R\&D in percentage of GDP (2001) & 0.31 & 0 & 2.38 & 0.59 \\
\hline Private R\&D in percentage of GDP (2001) & 0.02 & 0 & 5.27 & 0.94 \\
\hline $\begin{array}{l}\text { Percentage of high technology patents from total } \\
\text { (2001) }\end{array}$ & 0.6 & 0.1 & 341.9 & 26.41 \\
\hline Total number of patents (2001) & 3.1 & 0 & 781.6 & 130.68 \\
\hline GDP per capita in $€(2000)$ & 2.6 & 0.6 & 824.2 & 142.44 \\
\hline
\end{tabular}




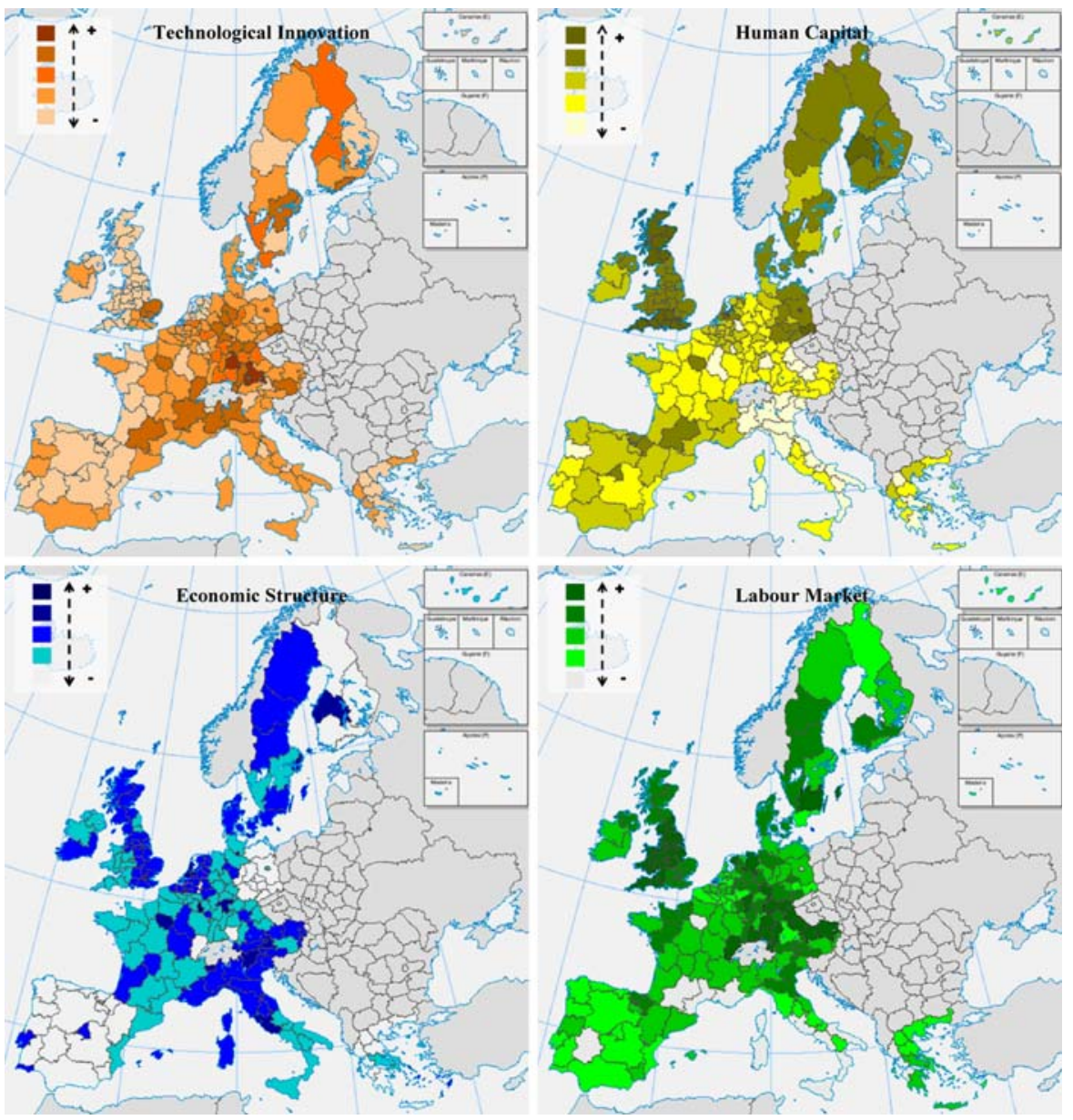

Fig. 1 Innovation latent dimensions. Source: own elaboration

public R\&D. ${ }^{3}$ Factor 3 (explaining 18,11\% of variance) is called Economic Structure because it includes GDP and the employment in services (usually correlated with higher levels of per capita production). Finally, Factor $4(11,24 \%)$ is named Labour Market availability, as it contains the level of employment and the rate of individuals with an intermediate education level. The regional loadings for each region help to interpret territorial behaviour in terms of these latent dimensions (Figure 1).

The pertinence of Cluster Analyses arise from an interest in classifying the different analysed cases and creating typologies of similar regions, in terms of the profiles of their performance in the latent dimension space. This analysis is used to define five

3 The Public Expenditure in R\&D has a very substantial part in the universities. Even when done outside the academic sphere it refers in general to Basic Investigation. In comparison, Private R\&D is more often Market-related Investigation. 
clusters of European innovation region systems. These regional clusters have five different profiles in terms of the latent dimensions of innovation. ${ }^{4}$

The Cluster 1 is called Large Economic Centres. It includes the 19 regions with the highest economic development, highest level of Human Capital, very strong in technology, but limited in terms of Labour Market Availability.It is the cluster that includes the capitals of the European Union. Examples of these regions are Ille de France, London, Comunidad de Madrid, Hamburg and Brussels.

Cluster 2 called Average Regions includes the 53 regions with an average level of development, average economic performances, average in labour market issues, high level in Human Capital, but considerably low in the Technological Innovation dimension. This cluster includes regions such as Catalonia, La Rioja, Bretagne, Scotland, Wales or Denmark.

Cluster 3 was named Disadvantaged Regions and is the group including the 47 regions with major gaps and limitations. These regions have the lowest values in three out of the four dimensions extracted, Technological Innovation, Economic Structure and Labour Market Availability. The Human Capital, despite not having the most negative values, is clearly adverse. This group is composed by a majority of regions from the south of Europe, Portugal, Spain, Greece, south of France and south of Italy. If we compare these with the eligible areas under objective 1 for structural funds 2004-2006 it is observed that both groups are quite similar.

Cluster 4, defined as Innovating Regions. is the most intense in Technological Innovation. It presents average levels of Human Capital and Economic Structure but with a strong score on Labour Market Availability. It is composed by a large group of Germanic regions, such as Cologne and Stuttgart (eleven out of thirteen), one Dutch and one Swedish region.

Cluster 5, Central Regions, includes 41 regions of Central Europe (Germany, France, Netherlands and Italy) which have the highest Labour Market Availability, high economic levels, with above average Technological Innovation and at the same time having the lowest ranking for Human Capital. Low performance on this dimension may be explained by the fact that this group of regions has the lowest values of Public R\&D compared to the other clusters.

The analysis of the spatial distribution of the clusters is of interest (Figure 2). The Disadvantaged Regions are concentrated in the southern member-states of Europe, Portugal, Greece, Spain, south of France and south of Italy. The Average Regions encircle the Central Regions. If the centre of Europe is defined as being near the centre of Germany where the first level is constituted by Innovating Regions, then a second level of Central Regions and a third of Average Regions, and a more peripheral level of Disadvantaged Regions emerge. The cluster, Large Economic Centres, is not spatially delimited because it is composed of the major or largest regions in terms of economic development. In general, it may be concluded that the analysis of the map

\footnotetext{
4 In our study we used a Hierarquical Cluster Analysis. The criteria to define how the cases are associated were the 'Wards', specially because it is a method that permits the construction of well balanced clusters in terms of number of cases included in each one. The way to choose the number of clusters was the analysis of the dendogram.
} 


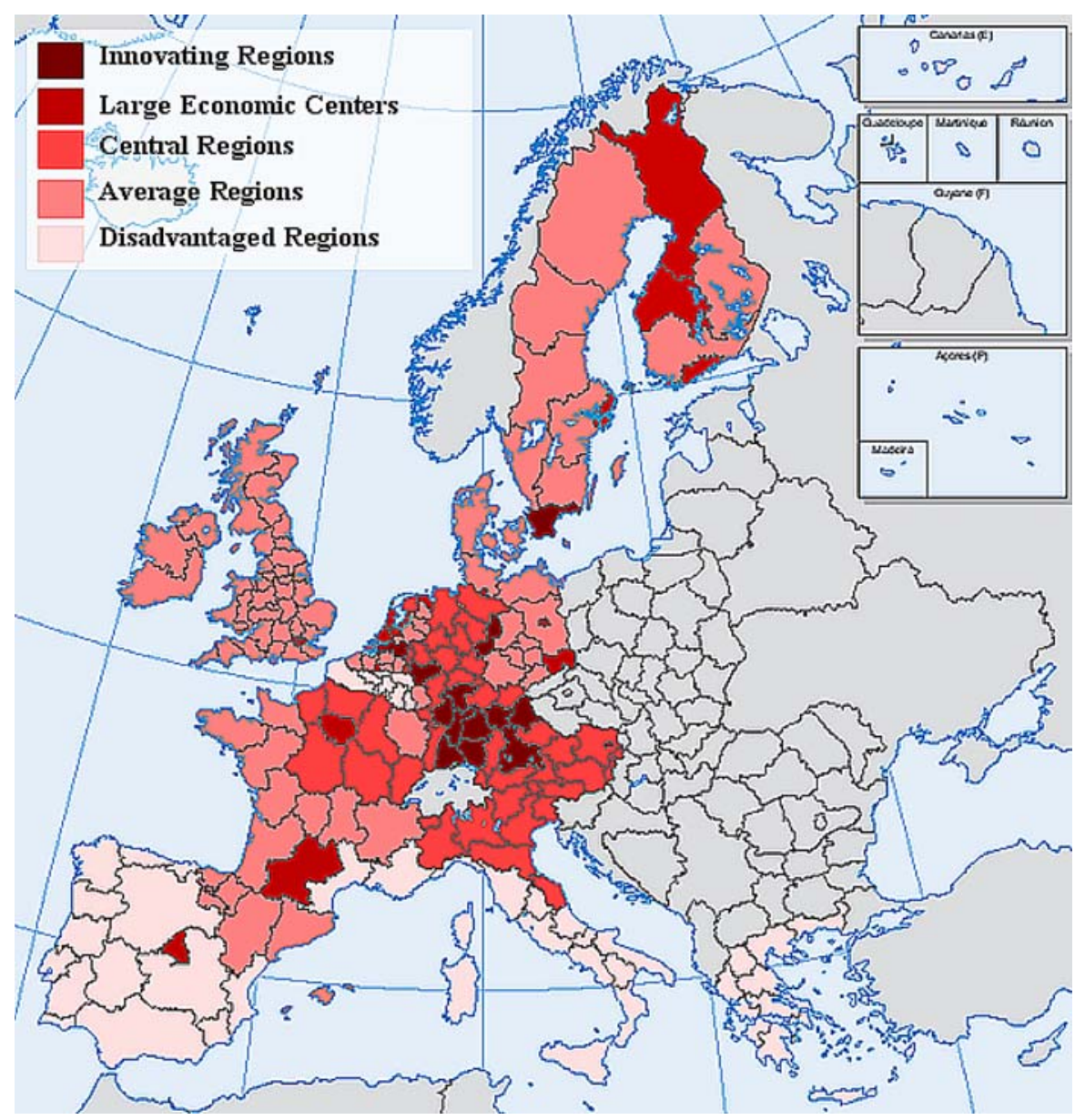

Fig. 2 Clusters spatial distribution. Source: Pinto (2007)

provides a view about the importance that proximity factors create in the innovative process, i.e., inclusion in a specific cluster is highly spatially dependent.

\section{Strategies and limits for innovation in the Algarve}

\subsection{Innovation strategies in the Algarve}

Regional Innovation Strategies, understanding that companies and other actors interact mainly within a regional and local context, look for regional dialogue that involves these actors in the analysis of the strengths, weaknesses, opportunities and threats leading agreed upon priorities to support innovation and implement related actions. The Algarve is one of the European regions that developed a Regional Innovation Strategy (RIS) to promote the creation and reinforcement of the Regional Innovation Systems 
and to increase regional competitiveness. According to the Innovating Regions in Europe Network (IRE, 2005) 33 regional innovation strategies (RIS, 1994-2001), 70 regional innovation and technology transfer strategies (RITTS, 1994-2001), 16 regional innovation strategies in countries recently associated with the EU (RIS-NAC, 2001-2004) and 33 projects of regional innovation strategies in new Member-States and associated countries (2005) have been developed with the support of the EU. On the other hand, 145 regions have developed Regional Programs within the scope of the European Regional Development Fund (ERDF) Innovative Actions, many of them as a continuation of the implementation of their Regional Innovation Strategy.

The Ettirse - Strategy of Technological Transfer and Innovation in the South-western part of Europe (2000-2001) was carried out by the CCDR Algarve ${ }^{5}$ and the Province of Huelva (Andalusia, Spain) is one of the few trans-border initiatives. The project developed two strategies of innovation and technological transfer with strong links and added value. Although there was some success, according to DG Regio, the project did not show significant advantages in grouping two RIS together because the complexity of each already was an ambitious goal. The INOVAlgarve (Regional Programme of Innovative Actions for the Region of the Algarve), the programme elaborated after Ettirse (executed in 2002-2003), gave support to several innovative enterprise initiatives and to the creation of CRIA (Regional Centre for the Innovation of the Algarve) to supply an interface between the university and the enterprises, promoting the emergence of start-ups and spin-offs. The success attained with the innovation strategies in the Algarve has been low and intermittent, with little continuity and has not obtained the support and participation of some of the relevant regional innovation actors, although it had did bring more attention to these matters.

\subsection{Limitations to RSI in the Algarve}

The European Commission (2002) was aware that RISs were having limited success. Some factors influencing this outcome are: regional authorities felt threatened by a transparent and inclusive bottom-up process; regional authorities felt threatened by an evident failure between supply and demand analysis of the SME (this limited the diffusion of the diagnosis made and the participation of these SME in the process); regional authorities did not put into practice ideas and results of the Regional Innovation Strategy; the existing institutions of Research, Development and Innovation felt threatened by the process and its conclusions, revealing a reluctance to move forward. At an operational level: failure in finding 'regional champions' and/or a high level of management of the Strategy that facilitated the progress of the networking process, providing political leadership and creating consciousness and involvement of regional actors; failure in keeping 'regional champions' and/or a high level of management of the Strategy that maintained progress in networking process; exaggerated attention paid to external consultants in the development of the strategy and the action plan without the attention and participation of the local actors; an extreme "technologypush" perspective without consideration of demand for the technology, absence of

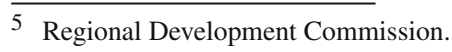


an adequate agreement for the functioning of the Regional Innovation System and its weaknesses; a more practical and applicable approach was needed instead of a theoretical one that discouraged the participation of the local actors, in particular enterprises. Although these factors were not all present in the Algarve RIS, they illustrate the challenges that still have to be overcome to reach a successful RSI.

The most important limiting factor according to Landabaso et al. (2003), also cited by the European Commission (2002) is that the majority of examples of less successful RIS result from weak public-private partnerships with limited Social Capital. Fukuyama (2001) defines Social Capital as the capacity of people to co-operate in a group based on common values. Regional actors that trust each other, developing positive virtues such as honesty, trust, reciprocity, and respect for commitments have the necessary aspects for cooperative behaviour. In this way the importance of Social Capital is illustrated. Further, it is confirmed by, for example the 4th Community Innovation Surveys' (CIS), OCES (2006), results reveal that the EU's most innovative regions are those with a high level of cooperation among the main actors. OECD (2005) also refers to the role of Social Capital for the reliable existence of knowledge, learning and a strengthened innovative environment.

The Algarve is in a complex situation regarding innovation. As referred to in the above comparative analysis of the European regions and as suggested by Cheshire and Malecki (2004), it is recognised that the innovative performance of a region is not independent from the performance of its neighbours. In other words, relations exist between physical proximity and the innovative processes and the effect of these factors can be strengthened with participation in innovation networks. In this way, one can accept with some consensus that the regions bordering the Algarve, the Alentejo and Andalusia, are not the most dynamic and, further, in many studies they are two of the poorest regions of the EU15 (Silva and Silva 2000 and Hollanders 2003).

On one hand, the Algarve faces the Regional Innovation Paradox which is the contradiction between the major need to invest in innovation in less developed regions such as the Algarve to promote economic convergence and its lower capacity to absorb such investment in innovative activities. On the other hand, the existence of proximity and agglomeration economies in developed regions creates an interest in investing more in these regions. Rodriguez-Pose (2001), analysing the European regions between 1986 and 1996, verified that the investment in R\&D has been concentrated on the richest regions. The impact of the investment in $R \& D$ in regions such as the Algarve could be limited because the level of expenditures in R\&D is too low in Portugal, in comparison to the more developed countries of EU and consequently it does not reach the minimum threshold enabling significant knowledge spill-overs. This low level results from a productive structure in which the primary and tertiary sectors which have a huge role in the economy are characterised by low R\&D investments. This problem impacts the Algarve deeply; the regional economy is based on tourism, allowing one of the biggest rates of economic growth with almost an absence of technological effort. This impasse has its origin between the lack of capacity to innovate on the one hand and on the other to absorb innovation. Portugal, in the author's experience, attempted to reduce this incapacity with regional development incentive policies, because expansion of the R\&D expenditures has been homogeneous in the regions outside of the Lisbon region. The increase of $\mathrm{R} \& \mathrm{D}$ expenditures in the regions has contributed to 
the sprouting of new universities and the promotion of the existing ones. But the public investment in $R \& D$ be an efficient form to reduce regional disparities? As most SMEs do not have R\&D capacities, they are based on the research carried out by state laboratories or universities, which is not an ideal form to minimise the existing gap because public supported research (most often basic research) creates a gap between research outcomes and findings and its conversion into useful knowledge in terms of product and process innovation and thus its impacts in the economy. The study of the Regional Innovation Paradox, Oughton et al. (2002), also showed that complementarity among companies, government and education in the financing of R\&D must try to answer both supply and demand issues. Regional government has a role in fortifying ties between government-industry-university and in developing regional learning policies and needs to be able to control some economic variables (for example in the arbitration of structural funds at a regional level). Thus, one understands that the lack of a regional government in the Portuguese regions, in particular in the Algarve, could be a strong constraint, because the CCDRs (Regional Development Coordination Commissions) do not have the political or legislative autonomy to conveniently adjust the strategies they apply. 6

\subsection{The regional innovation plan of the Algarve}

The previous elements demonstrated a need to evaluate the regional R\&D potential, innovation demand, and the existing cooperation networks, e.g., in the scientific fields of specialisation of the University of the Algarve. This is necessary in order to contribute towards the building of answers adjusted to the ambitions and strategic design of the region and the conception of a strategy to create a RSI in the Algarve to help ensure long run sustainable economic conditions. The process of elaboration of the PRIAlgarve - Algarve's Regional Innovation Plan, was based on the analysis and critical reconsideration of a set of documents, with the Ettirse, INOVAlgarve, the Regional Development Strategy 2000-2006 documents and the preparatory documents for the new programming period of 2007-2013 being the more prominent ones. The related diagnostic analysis used available documentation with origins in public administration, professional associations and academia. An extensive number of interviews were carried out with diverse regional entities and prominent enterprises and representative bodies of key-sectors trying in an effort to achieve a bottom-up supported strategy research process. The plan defined some key-sectors for the region, Tourism (central sector of regional economy), the Agro-food sector (crucial to diversification of the economic base), ICT (to consolidate the local Information Society), Sea (Algarve's strategic resource), Renewable energies (latent regional competitive advantage) and Life Sciences (an investment for the future). Brainstorming sessions involved elements of CRIA (Regional Centre for the Innovation of the Algarve) and responsible researchers from several units of R\&D of the university.

\footnotetext{
6 There remains a gap between the central government and the municipalities with the absence of a regional decision level. In 1998 a referendum was conducted in Portugal for the creation of administrative regions but this idea was rejected. There are some signs of political will to make a second referendum about the same issue.
} 
It is expected that PRIAlgarve will materialize with a set of projects to be executed through public-private partnerships developed in the region. This will grant access to funds from the CSF 2007-2013, from Regional Operational Programme and Thematic National Programmes but also from European Programmes such as the 7th Research Framework Programme or the Competitiveness and Innovation Framework Programme.

\section{Conclusions}

Innovation is, at the present time, one of the focuses of European regional policy. Its importance to economic growth is unquestionable. Regional level inequalities are easily observed, in terms of a diversity of indicators from GDP to education levels or unemployment. Regarding innovation, these disparities are not so easily demonstrated because this phenomenon is characterized by multiple factors that affect each territory differently.

The emergence of the Regional Innovation Systems (RSI) gives the regional level strengthened relevance, in analytical and policy-making points of view. The innovation panorama in the Algarve is not easy but efforts seem to be evolving in a direction that will contribute to increased regional competitiveness. The region presents different types of limitations that condition its innovative performance including little critical mass, unqualified specialisation, services with low technology requirements, human resources and little effort in R\&D all leading to limited innovation outputs. The interregional comparison with EU15 regions resulted in a Factor Analysis and an Analysis of Clusters, in which four latent dimensions were found (Technological Innovation, Human Capital, Economic Structure and Labour Market Availability) and five clusters with distinct behaviours in terms of the factors were identified: Disadvantaged Regions, Average Regions, Central Regions, Great Economic Centres and Innovating Regions. The Algarve belongs to the Disadvantaged Regions that congregated with regions having lower scores. The relevance of comparing regional performances using alternative methodologies is increased by the European Regional Policy that insists on using GDP $p c$ as the main indicator to understand the level of development of regions. When analysing the Regional Innovation System of the Algarve one understands, that it is still at a nascent stage of development, if it does indeed exist at all. The synthesis presentation of the Regional Innovation Strategies in the Algarve, Ettirse and INOVAlgarve, show that, although there have been some limitations and relative failures, the region and in particular public institutional actors have been concerned about how to develop this theme. The construction of a Regional Innovation System in the Algarve has been limited primarily by, the absence of effective public-private partnerships, limited Social Capital, non existence of a R\&D platform that propels increased incomes and investments and the absence of a regional government that leads and co-ordinates the process.

To respond to these issues, the CCDR Algarve prepared its Regional Innovation Plan, in line with the Operational Program of the Algarve for 2007-2013 and also with the Thematic Operational Programs, and European programmes, such as the Framework Programme for Competitiveness and Innovation. It is expected that the 
Regional Innovation Plan will produce guidelines that are appropriate and used by the diverse regional actors, in a way to consolidate a true Regional Innovation System.

\section{References}

Abramovitz M (1962) Economic growth in the United States: a review article. Am Econ Rev 4:762-782 Acs ZJ, Varga A (2002) Geography, endogenous growth and innovation. Int Reg Sci Rev 25(1):132-148 Amable B, Petit P (2002) The diversity of social systems of innovation and production in the 1990s, article for scientific journal, available in URL http://www.cepremap.cnrs.fr/couv_orange/co0115.pdf in $17-08-2005$

Braczyc HJ, Cooke P, Heidenreich M (eds) (1998) Regional innovation systems - the role of governances in a globalized world, 1st edn. UCL Press, London

Cheshire PC, Malecki EJ (2004) Growth, development, and Innovation: a look back and forward. Pap Reg Sci 83:249-267

Cooke P (1998) Origins of the concept. In: Braczyc HJ, Cooke P, Heidenreich M (eds) Regional innovation systems - the role of governances in a globalized world, 1st edn. UCL Press, London

Denison F (1967) Why growth rates differ: post-war experience in nine western countries. The Brooking Institution, Washington

Doloreux D, Bitard P (2005) Les systèmes régionaux d'innovation : discussion critique. Géographie Économie Société 7:21-36

European Commission (2002) Regional innovation strategies under the european regional development fund innovative actions 2000-2002. DG Regio, Brussels

European Commission (2004) A new partnership for cohesion-third report on economic and social cohesion. Office for Official Publications of the European Communities, Luxembourg

European Commission (2005) Third progress report on cohesion: Towards a new partnership for growth, jobs and cohesion. Communication of the Commission, Bruxelles

Evangelista R, Iammarino S, Mastrostefano V, Silvani A (2001) Measuring the regional dimension of innovation-lessons from the Italian innovation survey*1. Technovation 21:733-745

Fagerberg J (1991) Innovation, catching-up and growth in OECD (1991), 37-48

Fagerberg J, Verspagen B, Carriels M (1997) Technology, growth and unemployment across European regions. Reg Stud 31(5):447-466

Ferrão J (2002) Inovar para desenvolver: o conceito de gestão de trajectórias territoriais de inovação, Interacções—Revista Internacional de Desenvolvimento local, vol 3(4):17-26

Freeman C (1995) The national system of innovation in historical perspective. Cambr J 19:5-24

Fukuyama F (2001) Capital Social e Globalização. In: Gulbenkian FC (eds) Globalização, Desenvolvimento e Equidade, Publicações Dom Quixote, Lisbon

Guerreiro J (2005) As funções da universidade no âmbito dos Sistemas de Inovação. In: VÁRIOS, Estudos II, Faculdade de Economia da Universidade do Algarve, Faro, pp 131-148

Hollanders H (2003) 2003 European innovation scoreboard: Technical Paper no.3 regional innovation performances, European Commission DG Enterprise, Bruxelles

IRE Network (2005) Innovating regions in Europe-strategies making a difference, flyer, IRE, Luxembourg

Kline S, Rosenberg N (1986) An overview of innovation. In: Landau R, Rosenberg N (org.) (1986) The positive sum strategy: harnessing technology for economic growth. National Academic Press, Washington DC, pp 275-305

Landabaso M, Mouton B, Miedzinski M (2003) Regional innovation strategies (RIS): a tool to improve social capital and institutional efficiency. ERIK Network Newsletter 1:8-10

Lucas R (1988) On the mechanics of economic development. J Monet Econ 22:3-42

Lundvall B-A (ed) (1992) National systems of innovation: towards a theory of innovation and interactive learning, 1st edn. Pinter Publishers, London

Nelson R (ed) (1993) National systems of innovation: a comparative studies. University Press, Oxford

OCES (2006) $4^{\circ}$ Inquérito Comunitário à Inovação (CIS 4), online document available in URL http://www. estatisticas.gpeari.mctes.pt/ in 31-03-2008

OECD (2005) Oslo manual-guidelines for collecting and interpreting innovation data, 3rd edn. OECD Publications, Paris

Oughton C, Landabaso M, Morgan K (2002) The regional innovation paradox: innovation policy and industrial policy. J Technol Transf 27:97-110 
Pestana MH, Gageiro JN (2003) Análise de Dados para Ciências Sociais—A complementaridade do SPSS. Edições Sílabo, Lisbon

Pinto H (2006a) A Performance do Algarve na Inovação-Uma Comparação Inter-regional, Dissertação de Mestrado, not published, Universidade do Algarve, Faro

Pinto H (2006b) Contributos para o Plano Regional de Inovação do Algarve, not published, CRIA—Centro Regional para a Inovação do Algarve, Faro

Rodriguez-Pose A (2001) Is R\&D in lagging areas of Europe worthwhile? Theory and empirical evidence. Pap Reg Stud 80:275-295

Romer P (1986) Increasing returns and long run growth. J Polit Econ 94(51):1002-1037

Romer P (1990) Endogenous technical change. J Polit Econ 98(5):S71-S101

Silva S, Silva MR (2000) Crescimento Económico nas regiões Europeias: Uma avaliação sobre a persistência das disparidades regionais no período 1980-95, FEP Working Papers 96, Universidade do Porto, Faculdade de Economia do Porto

Solow R (1956) A contribution to the theory of economic growth. Q J Econ 70:65-94

Solow R (1957) Technological change and the aggregate Production function. Rev Econ Stat 39:312-320

Uyarra E (2007) Regional innovation systems in perspective, conceptual relevance and policy challenges. In: Conference proceedings, 1st international seminar on regional innovation policies, Porto 